\title{
Family and School Socioeconomic Disadvantage: Interactive Influences on Adolescent Dating Violence Victimization
}

\author{
Aubrey L. Spriggs, \\ University of North Carolina at Chapel Hill, Chapel Hill, NC UNITED STATES \\ Carolyn Tucker Halpern, Ph.D., \\ University of North Carolina at Chapel Hill
}

Amy H Herring, Sc.D., and

University of North Carolina at Chapel Hill

Victor J Schoenbach, Ph.D.

University of North Carolina at Chapel Hill

\begin{abstract}
Although low socioeconomic status has been positively associated with adult partner violence, its relationship to adolescent dating violence remains unclear. Further, few studies have examined the relationship between contextual disadvantage and adolescent dating violence, or the interactive influences of family and contextual disadvantage. Guided by Social Disorganization Theory, Relative Deprivation Theory, and Gendered Resource Theory, we analyzed data from the U.S. National Longitudinal Study of Adolescent Health (1994-1996) to explore how family and school disadvantage relate to dating violence victimization. Psychological and minor physical victimization were self-reported by adolescents in up to six heterosexual romantic or sexual relationships. Family and school disadvantage were based on a principal component analysis of soecioeconomic indicators reported by adolescents and parents. In weighted multilevel random effects models, between-school variability in dating violence victimization was proportionately small but substantive: $10 \%$ for male victimization and 5\% for female victimization. In bivariate analyses, family disadvantage was positively related to victimization for both males and females; however, school disadvantage was only related to males' physical victimization. In models adjusted for race/ethnicity, relative age within the school, and mean school age, neither family nor school disadvantage remained related to males' victimization. For females, family disadvantage remained significantly positively associated with victimization, but was modified by school disadvantage: family disadvantage was more strongly associated with dating violence victimization in more advantaged schools. Findings support gendered resource theory, and suggest that status differentials between females and their school context may increase their vulnerability to dating violence victimization.
\end{abstract}

\section{Keywords}

USA; adolescent; dating violence; gender differences; school; socioeconomic status (SES); family

(C) 2009 Elsevier Ltd. All rights reserved.

Corresponding author spriggs@email.unc.edu.

Publisher's Disclaimer: This is a PDF file of an unedited manuscript that has been accepted for publication. As a service to our customers we are providing this early version of the manuscript. The manuscript will undergo copyediting, typesetting, and review of the resulting proof before it is published in its final citable form. Please note that during the production process errors may be discovered which could affect the content, and all legal disclaimers that apply to the journal pertain. 


\section{INTRODUCTION}

Dating violence is a serious and prevalent problem in the United States. In the 1995-96 school year, thirty-two percent of male adolescents and thirty-one percent of female adolescents in opposite-sex romantic relationships reported psychological or physical victimization in one or more relationships in the preceding 18 months (Halpern, Oslak, Young, Martin, \& Kupper, 2001). Cross-sectional studies document dating violence victimization is correlated with negative reproductive health outcomes among female adolescents, and with poor mental health outcomes among female and male adolescents (Decker, Silverman, \& Raj, 2005; Lehrer, Buka, Gortmaker, \& Shrier, 2006; Olshen, McVeigh, Wunsch-Hitzig, \& Rickert, 2007; Roberts, Auinger, \& Klein, 2005). In one longitudinal study, victimization onset was associated with increased depressive symptomatology among males and females, and increased involvement in substance use, antisocial behavior, and suicidal behavior among females (Roberts, Klein, \& Fisher, 2003). Adolescent dating violence victimization is associated with an increased risk for adult partner violence victimization among females (Lehrer et al., 2006), and victimization duration is positively associated with health consequences' severity (Bonomi, Thompson, Anderson, Reid, Carrell, Dimer et al., 2006; Johnson \& Leone, 2005). Adult victimization is associated with injury and mortality, although rates of such outcomes are greater for females than males (Field \& Caetano, 2005; Tjaden \& Thoennes, 2000). Given the prevalence of adolescent partner violence, and its connection with health and developmental outcomes, understanding its etiology is of concern to researchers and policymakers.

Longitudinal research on adolescent dating violence has identified a number of individual and familial predictors for victimization onset, but these tend to vary by gender and severity of violence outcomes being studied. For females, risk factors for psychological and minor physical abuse onset include age, childhood maltreatment, African American race, living with neither biologic nor step parents, low parent education, delinquent behavior, sexual intercourse in the relationship, and physical maturity (Foster, Hagan, \& Brooks-Gunn, 2004); for serious physical and sexual victimization, risk factors include alcohol use, being hit by an adult, having a friend who is a dating violence victim, and depression (Buzy, McDonald, Jouriles, Swank, Rosenfield, Shimek et al., 2004; Foshee, Benefield, Ennett, Bauman, \& Suchindran, 2004). For males, risk factors for psychological and minor physical victimization onset have largely been unstudied, except for sexual intercourse with a female partner (Kaestle \& Halpern, 2005); predictors of serious physical victimization onset include being hit by an adult as a child, low self-esteem, and having been in a fight with a peer (Foshee et al., 2004). Such research provides knowledge regarding individual factors subject to intervention, but does not address how adolescent partner violence is influenced by wider structural forces.

From an ecological model of health or fundamental causes of disease framework, understanding social structural forces that influence health outcomes is essential in addressing root causes (Link \& Phelan, 1995). Such structural factors, including neighborhood poverty, have been connected with many other health outcomes, including self-rated health, birth weight, ischemic stroke, ischemic heart disease, and all-cause mortality, though these associations often vary in strength by gender (Chaix, Rosvall, \& Merlo, 2007; Do, Finch, Basurto-Davila, Bird, Escarce, \& Lurie, 2008; Lisabeth, Diez Roux, Escobar, Smith, \& Morgenstern, 2007; Masi, Hawkley, Piotrowski, \& Pickett, 2007; Turrell, Kavanagh, Draper, $\&$ Subramanian, 2007). The purpose of this paper is to extend the understanding of potential fundamental contributors to adolescent dating violence victimization by examining its relationship to family and school socioeconomic disadvantage. We examine these determinants separately for male and female adolescents, as past studies have found that female perpetration against male partners often arises in response to aggression initiated by male partners ( $\mathrm{O}$ 'Keefe \& Treister, 1998), and the consequences of victimization tend to be more severe for females (Field \& Caetano, 2005; Tjaden \& Thoennes, 2000). Further, studies of adult intimate partner 
violence suggest that many forms of partner violence are rooted in gender inequality (Pallitto \& O'Campo, 2005). As such, examining male and female victimization separately is needed to inform future prevention program efforts.

\section{Individual/Family Socioeconomic Disadvantage}

Although partner violence affects couples in all socioeconomic strata, research supports an inverse relationship between socioeconomic status and adult violence (Aldarondo \& Sugarman, 1996; Breiding, Black, \& Ryan, 2008; Cunradi, Caetano, \& Schafer, 2002). Some researchers hypothesize that the financial strain and social isolation resulting from lower socioeconomic status creates relationship stress that in turn increases the likelihood of partner violence (Straus, Gelles, \& Steinmetz, 1980). Whether differential risk by socioeconomic status begins in adolescence, however, is unclear. Family-of-origin socioeconomic status could influence adolescent dating violence through adolescent risk behaviors or mental health, increasing exposure to family-of-origin violence, or influencing the adoption of traditional gender ideologies. Although in some studies family-of-origin socioeconomic status was significantly inversely related to dating violence victimization (Foster et al., 2004; Halpern et al., 2001; O'Keefe, 1998), it was unrelated in others (Foshee et al., 2004; Foshee, Linder, MacDougall, \& Bangdiwala, 2001; O'Keefe \& Treister, 1998). However, because studies of dating violence have primarily focused on studying other factors, they may underestimate effects by including variables that mediate socioeconomic status and victimization. Further, findings' generalizability is unclear because most studies have used geographically restricted samples.

\section{Contextual Socioeconomic Disadvantage}

Research examining neighborhood contexts and partner violence has focused primarily on adults. In ecological analyses, Browning (2002) found that neighborhood disadvantage was positively related to female-victim intimate partner homicide; however, disadvantage was unrelated to individual-level severe partner violence victimization after individual sociodemographic, social support, and relational characteristics were controlled (Browning, 2002). In another study, authors found that for both black and white adult couples, neighborhood poverty was positively associated with female-perpetrated violence; however, neighborhood poverty was positively associated with male perpetration among black couples only (Cunradi, Caetano, Clark, \& Schafer, 2000).

The influence of contextual disadvantage is understudied in the adolescent dating violence literature, despite findings that contextual disadvantage is related to dating violence risk factors. For example, neighborhood disadvantage (i.e., high poverty, unemployment, and residential turnover) and school disadvantage (i.e. percent of poor students or families on public assistance) have been associated with depression, early sexual activity, and substance use (Cubbin, Santelli, Brindis, \& Braveman, 2005; Harris, Duncan, \& Boisjoly, 2002; O’Malley, Johnston, Bachman, Schulenberg, \& Kumar, 2006; Oetting, Donnermeyer, \& Deffenbacher, 1998; Wight, Botticello, \& Aneshensel, 2006). In the one study exploring contextual disadvantage associations with dating violence, neighborhood disadvantage (i.e., percent below poverty, unemployed, nonwhite, renting housing, and female-headed households) was found unrelated to dating violence perpetration trajectories in either crude or adjusted analyses (Foshee, Karriker-Jaffe, Reyes, Ennett, Suchindran, Bauman et al., 2008). However, as the study was conducted in one rural county, generalizeability may be limited; further, variations in associations by family disadvantage and by gender were not explored.

\section{Interaction Between Individual and Contextual Disadvantage}

Another possibility is that the influence of family disadvantage on dating violence varies by contextual disadvantage. Such an interaction may explain why prior findings regarding family 
socioeconomic status have been mixed. In the adult partner violence literature, the influence of individual socioeconomic status has been found to vary across couple contexts, and by gender. Having a lower educational or occupational status compared to a partner has been positively associated with male but not female partner violence perpetration (Anderson, 1997; Atkinson, Greenstein, \& Lang, 2005). The influence of family socioeconomic status on adolescent outcomes has been found to vary by contextual disadvantage and gender as well. For example, relative disadvantage within school has been associated with decreases in selfesteem in the transition to middle school, especially among male adolescents (Rhodes, Roffman, Reddy, Fredriksen, \& Way, 2004). As low self-esteem is a risk factor for dating violence perpetration, especially among low-SES adolescents, (Pflieger \& Vazsonyi, 2006), a connection between relative disadvantage and dating violence seems plausible. Results for these and other studies suggest that relative disadvantage may be differentially related to dating violence victimization by gender.

\section{Theoretical Model}

This analysis draws upon social disorganization theory, relative deprivation theory, and gendered resource theory in exploring how family and school socioeconomic disadvantage relate to adolescent dating violence victimization. According to social disorganization theory, the material and structural resources of communities affect social cohesion, and subsequently communities' effectiveness in regulating residents' behavior (Sampson, 1997; Sampson, Raudenbush, \& Earls, 1997). Similarly, school disadvantage has been negatively associated with parent involvement (Hooverdempsey, Bassler, \& Brissie, 1987), which can negatively affect the development of bonds and informal networks between parents within that school. As in neighborhood social settings, without this "network closure" (Coleman, 1988), the collective monitoring and social control of adolescent behavior likely will be weaker. The bonds between parents within schools should be influential in adolescent dating violence, given the importance of school settings in the formation of adolescent intimate relationships (Ford, Sohn, \& Lepkowski, 2001, 2003). One implication of social disorganization theory is that contextual disadvantage affects everyone operating within that context; therefore, we would expect a positive association between school disadvantage and dating violence victimization for both male and female adolescents.

In contrast, relative deprivation theory emphasizes how contextual disadvantage moderates the association between family disadvantage and the outcome studied. According to this perspective, deprivation is something that is individually perceived, and is constructed through a process of social comparison with a salient frame of reference (Webber, 2007). For adolescents, a salient frame of reference is their school environment. Applying this theory, we would expect adolescents who are disadvantaged relative to their same-school peers to be at higher risk for dating violence victimization; further, this association should not vary by gender.

Finally, unlike both the above theories, gendered resource theory predicts gender differences in the effects of relative disadvantage (Anderson, 1997; Atkinson et al., 2005). That is, we expect relative disadvantage to be more strongly related to female than male victimization. Such a prediction is based upon two premises. First, partnerships tend to be homogamous along sociodemographic characteristics (Ford, Sohn, \& Lepkowski, 2002); therefore relatively disadvantaged females will likely be paired with relatively disadvantaged males. Second, relative socioeconomic disadvantage is more threatening to traditional masculine versus feminine gender roles (Anderson, 1997; Atkinson et al., 2005); therefore relative socioeconomic disadvantage may prompt violence perpetration as a means to reassert power more often by males than females. 


\section{METHODS}

\section{Data}

We utilized data from the National Longitudinal Study of Adolescent Health's (Add Health) contractual data set (Udry, 2003). Add Health is a prospective cohort study of a nationallyrepresentative sample of youth enrolled in grades 7-12 in the 1994-95 school year (Wave I) (Harris, Florey, Tabor, Bearman, Jones, \& Udry, 2003). Respondents were followed up one year after baseline (1996, Wave II). Add Health utilized a multistage probability sampling design to obtain its Wave I sample. The first stage was a stratified, random sample of all public and private high schools in the U.S. A feeder school was also recruited from each participating community. In-school surveys were attempted with all students. In the second stage, a sample of adolescents was drawn for in-depth in-home interviews, consisting of a core sample plus selected oversamples. The parent (mother prioritized) or primary caretaker of Wave I in-home interview participants was also recruited for an in-home interview. Persons who completed Wave I in-home interviews were eligible to participate at Wave II, with a few exceptions (e.g., respondents who were high school seniors at Wave I).

\section{Measures}

Outcome-Adolescent dating violence victimization was based on five items from the Conflict Tactics Scale 2 (CTS2) (Straus, Hamby, Boney-McCoy, \& Sugarman, 1996) that were included in the Wave II in-home questionnaire; in some cases, item wording was slightly modified. For each of up to six romantic and/or sexual relationships reported, respondents were asked whether during the relationship their partner had ever done any of the following acts (yes or no): (1) "call you names, insult you, or treat you disrespectfully in front of others?" (2) "swear at you?" (3) "threaten you with violence?" (4) "push or shove you?" and/or (5) "thrown something at you that could hurt you?" A nominal summary variable with three mutuallyexclusive categories was constructed: no victimization (no acts reported in any relationship or no relationships reported), psychological victimization (any of acts 1-3 reported and none of acts 4-5), and physical victimization (any of acts 4-5 reported, regardless of response to acts 1-3). This categorization is consistent with past studies (Halpern et al., 2001; Halpern, Young, Waller, Martin, \& Kupper, 2004) and is based on very few respondents reporting physical without psychological victimization.

Predictors-The predictor individual/family disadvantage was constructed using several indicators for family socioeconomic status. Variables were chosen to be consistent with past studies studying social disorganization, and included (all measured as yes/no): not living with both biologic parents, family receives public assistance, parent reports difficulty paying bills, highest parent education less than high school, and having an unemployed parent (defined as not currently working for pay and seeking paid employment) (Browning, 2002; Cunradi et al., 2000; De Coster, Heimer, \& Wittrock, 2006; Wight et al., 2006). We applied polychoric principal components analysis, and used factor loadings on the first principal component as item weights in generating the summary score.

The second predictor variable, school disadvantage, was based on the school-level prevalence of each family disadvantage indicator; items demonstrated good internal reliability (Cronbach's $\alpha=0.82$ ). Because some groups were oversampled, and weights for selection probability within schools are not available, the school aggregate variable was based on Add Health core sample respondents. After standardizing all variables (mean $=0$, standard deviation $=1$ ), a principal component analysis was run (eigenvalues presented in Table 2). Factor loadings on the first principal component were used as item weights in generating the summary score. 
Controls-Demographic covariates were included for individual-level dating violence victimization risk factors which may also be related to selection into schools characterized by concentrated disadvantage. These variables were derived from adolescent self-report at Wave II interview. Demographic control variables were age (group mean centered) and race/ethnicity (Non-Hispanic White, Non-Hispanic Black, Hispanic, Other). Gender was treated as a potential effect modifier, and all analyses were conducted stratified by gender. Indicators for other individual adolescent problem behaviors and mental health were not included, as they may either be mediators of the context-victimization relationship, or they may be effects of victimization itself. One school-level control variable was included - mean age within the school (grand mean centered).

\section{Analytic Sample}

We utilized five inclusion criteria. The base number of persons who participated in both Waves I and II and who had valid sampling weights available was 13,568. Respondents who did not report exclusively heterosexual relationships at Wave II were excluded $(n=269)$ because past research has found risk factors for partner violence to vary across opposite-sex and same-sex couples (Halpern et al., 2001; Halpern et al., 2004). Also, respondents whose parents were not interviewed $(n=1,606)$ or who were missing data on any of the individual-level covariates $(\mathrm{n}=1,043)$ were excluded. The resulting analytic sample size was 10,650 . Respondents who reported no romantic or sexual relationships at Wave II $(n=3,268)$ were included, as one strategy adolescents may use to avoid partner violence is to abstain from such relationships.

\section{Analyses}

All analyses were performed in Stata version 9 (StataCorp LP, College Station, Texas). Individual-level analyses included corrections for complex survey design and were weighted to yield nationally-representative estimates. Multilevel multinomial logistic regression analyses with random effects were conducted using GLLAMM commands and included weights for both individuals and schools (Rabe-Hesketh \& Skrondal, 2006; Rabe-Hesketh, Skrondal, \& Pickles, 2004). The estimation procedure used was numerical integration (10 integration points) with adaptive quadrature (Rabe-Hesketh et al., 2004). At Level-1, age was group mean centered, and race/ethnicity was entered as three dummy variables (non-Hispanic white as referent). Individual disadvantage was left on its original continuous scale, centered at the grand mean. Level-2 variables (mean age in school and concentrated disadvantage) were grand mean-centered. Level-2 variables were left on their original continuous scale because a visual examination of bivariate scatterplots (i.e., each level-two variable against school prevalence of victimization) indicated no curvilinear or threshold relationships.

Analyses began by examining univariate distributions and bivariate relationships. Proportions and means of partner violence victimization, individual-level confounders, and school-level variables were calculated. The bivariate relationship between each covariate and the victimization outcomes was assessed with a series of bivariate multilevel multinomial logistic regression models with random intercepts.

For subsequent multivariable analyses, the final full model was: Level 1 model:

$$
\begin{array}{r}
\eta_{i j k}=\beta_{0 j k}+\beta_{1 j k}\left(\mathrm{FD}_{\mathrm{ij}}\right) \\
+\sum_{p=2}^{P} \beta_{p j k} X_{p i j}
\end{array}
$$

Level 2 model: 


$$
\begin{aligned}
& \beta_{0 j k}=\gamma_{00 k}+\gamma_{01 k}\left(\mathrm{AGE}_{\mathrm{j}}\right)+\gamma_{02 k}\left(\mathrm{SD}_{\mathrm{j}}\right)+\mu_{0 j} \\
& \beta_{1 j k}=\gamma_{10 k}+\gamma_{11 k}\left(\mathrm{SD}_{\mathrm{j}}\right)+u_{1 j} \\
& \beta_{p j k}=\gamma_{p 0 k} \quad(\text { for } p>1) \\
& {\left[\begin{array}{c}
u_{o j} \\
u_{1 j}
\end{array}\right] \sim \mathrm{N}\left(\left[\begin{array}{l}
0 \\
0
\end{array}\right],\left[\begin{array}{l}
\tau_{00} \\
\tau_{01} \tau_{11}
\end{array}\right]\right)}
\end{aligned}
$$

Where $i$ indexes individuals within schools, $j$ is an index for schools, $p$ is an index for individual-level covariates, and $k$ indexes the outcome (psychological or physical victimization). The predicted $\log$ odds of dating violence victimization $(\eta)$ is modeled as a function of the school mean log odds of victimization $\left(\beta_{0 j k}\right)$, family disadvantage $\left(\mathrm{FD}_{\mathrm{ij}}\right)$, and the vector of individual-level covariates $\left(\mathrm{X}_{\mathrm{pij}}\right)$, which were the same for both physical and psychological victimization; all covariates except family disadvantage were entered as individual-level fixed effects. We model the school mean log odds of victimization $\left(\beta_{0 j k}\right)$ as a function of the grand mean of the log odds of victimization $\left(\gamma_{00 k}\right)$, school mean age $\left(\mathrm{AGE}_{\mathrm{j}}\right)$, school disadvantage $\left(\mathrm{SD}_{\mathrm{j}}\right)$, and the random effect for school $j\left(u_{0 j}\right)$. The slope for individual disadvantage $\beta_{1 j k}$ is modeled as a function of the grand mean of these slopes $\left(\gamma_{10 k}\right)$, school disadvantage $\left(\mathrm{SD}_{\mathrm{j}}\right)$, and the random effect for school $j\left(u_{1 j}\right)$. We assume that the random effects for both the intercept and slope are normally distributed with means of zero, variance of $\tau_{00}$ for the intercept and $\tau_{11}$ for the slope, and a covariance between the intercept and slope of $\tau_{10}$.

Four models were fit separately for female and male participants. First, to assess the level of variability in gender-specific dating violence victimization across schools, an intercept-only model with random intercepts was run to calculate the intraclass correlation coefficient (ICC). The level-1 variance was assumed to equal that of a logistic distribution $\left(\pi^{2} / 3\right)$ (Raudenbush $\&$ Bryk, 2002), and the ICC was calculated as $\left(\tau_{00}\right) /\left(\tau_{00}+\left[\pi^{2} / 3\right]\right)$. We did not conduct significance testing for random effect variance estimates because likelihood ratio tests are invalid with weighted data (Sribney, 2005), and Wald chi-square tests can be overly conservative when testing against the parameter boundary value (zero) (Fitzmaurice, Laird, \& Ware, 2004). Instead, we examined the magnitude and relative precision of the variance estimates. In the second model, we tested the relationship between family disadvantage and dating violence victimization net of control variables by adding level-1 fixed effects for all individual-level variables, as well as the school mean age variable. In the third model, we examined the direct influence of school disadvantage over and above family disadvantage by adding the school disadvantage score. We assessed the influence of school disadvantage both by examining the magnitude and statistical significance of the regression coefficient, and by examining the relative change in unexplained intercept variance. In the final model, we assessed whether the influence of family disadvantage on dating violence victimization varied by school disadvantage by adding a random slope for family socioeconomic disadvantage, as well as a cross-level interaction between family and school disadvantage. All individual-level variables were maintained in multivariable models because of the theoretical need to control for factors related to selection into schools.

\section{RESULTS}

\section{Descriptive Results}

Descriptive statistics for the sample are presented in Table 1 . The majority of respondents reported non-Hispanic white race/ethnicity (71.2\% females, $71.3 \%$ males). Mean scores for family disadvantage were -0.60 for females and -0.63 for males, and mean age was 16.3 years for females and 16.5 years for males. Overall, among female respondents, $13.8 \%$ reported psychological and $8.1 \%$ reported physical victimization by at least one romantic or sexual 
partner in the 18 months prior to Wave II interview; among male respondents, $13.6 \%$ reported psychological and $7.1 \%$ reported minor physical victimization in the same time period. Information regarding schools' characteristics is presented in Table 2. The mean genderspecific school prevalences of dating violence victimization were slightly different from the corresponding overall population-weighted prevalences (females $18.7 \%$ psychological, $8.7 \%$ minor physical; males $18.2 \%$ psychological, $7.6 \%$ minor physical). Concentrated disadvantage scores across schools were distributed approximately normally (mean $=0$, standard deviation $[\mathrm{SD}]=1$ ), with some right-skewness.

\section{Bivariate Results}

Results from bivariate multilevel multinomial logistic regression models are presented in Table 3. Gender differences were observed in patterns of associations. Relative age within school and school mean age were significantly positively related to psychological and physical victimization among both female and male participants. Race/ethnicity was significantly related to victimization only among males: non-Hispanic black, Hispanic, and non-Hispanic other males evidenced higher odds of physical victimization compared to non-Hispanic white males. Although family disadvantage was positively associated with females' physical victimization and males' psychological and physical victimization, school-level disadvantage was positively related only to males' physical victimization.

\section{Multivariable Results}

Females-Multivariable results for females are presented in Table 4. The first model, an intercept-only model, suggests proportionately small but important variation across schools in female dating violence victimization. The ICC indicates that about $5 \%$ of females' victimization variability is due to differences between schools. After addition of individuallevel covariates and school mean age in model two, about $36 \%$ of the between-school variation in female dating violence victimization is explained. Family disadvantage remains significantly positively associated with females' physical victimization after controlling for age and race/ ethnicity. In model three, school disadvantage was added and remained unrelated to females' victimization; unexplained between-school variability in dating violence victimization remained unchanged after adding school disadvantage. In model four, a cross-level interaction between family and school disadvantage was found to be highly significant. At the average level of school disadvantage (i.e., where the interaction term would be equal to zero), family disadvantage was found to be significantly related to an increased odds of both psychological and physical victimization among females. Further, family disadvantage was more strongly related to females' victimization in more advantaged schools (Figures 1 and 2). Variability by school disadvantage appeared greater for psychological compared to physical victimization. For example, the predicted probability of psychological victimization for a non-Hispanic white, average-aged female, with a family disadvantage score one standard deviation above average is $11 \%$ lower in a school one standard deviation above versus one standard deviation below the school disadvantage mean.

Males-Multivariable results for males are presented in Table 5. The intercept-only model suggests that differences across school contexts in males' victimization are greater than for females. The ICC indicates that about $10 \%$ of males' dating violence victimization variability is due to differences between schools. After addition of individual-level covariates and school mean age in model two, about $38 \%$ of the between-school variation in male dating violence victimization is explained. Notably, the modest associations between family disadvantage and males' victimization found in crude models are reduced and no longer significant in the adjusted model (psychological victimization $\mathrm{OR}=1.20, \mathrm{AOR}=1.14$; physical victimization $\mathrm{OR}=1.33$, $\mathrm{AOR}=1.13$ ); however, nonwhite race/ethnicity remains significantly positively related to males' physical victimization. In model three, school disadvantage was added and was found 
to be unrelated to males' victimization after adjusting for other individual characteristics and school mean age. In model four, a cross-level interaction between family and school disadvantage was found to be small in magnitude and nonsignificant, suggesting that the association between family disadvantage and males' dating violence does not vary substantially by school disadvantage levels.

\section{DISCUSSION}

Although prior research documents a disproportionate burden of adult partner violence by lower socioeconomic status, relationships between family disadvantage and adolescent dating violence have been inconsistent. Despite evidence supporting relative disadvantage as a risk factor for adult partner violence, and evidence relating relative disadvantage to other adolescent outcomes, whether family and contextual disadvantage interact to affect adolescent dating violence is unknown. We address these gaps in the current study.

Between-school variability in dating violence victimization, even if proportionately small, was substantial for both males and females. The intraclass correlations should be considered in the context of other studies of adolescent risk behavior (e.g., alcohol and cigarette use) that find school-level intraclass correlations typically between 0.01 and 0.03 (Murray \& Short, 1997; Smolkowski, Biglan, Dent, \& Seeley, 2006). Even after adjusting for family-level disadvantage, age, and race/ethnicity, ICCs remained at 0.04 for girls and 0.06 for boys. Differences with prior studies could reflect that dating violence is more variable than other risk behaviors across school contexts; however, they also could reflect different individual-level control variables utilized.

The predictions of social disorganization theory were not supported among female respondents and were supported among male respondents only before adjustment for family disadvantage. These findings extend past studies which found no association between Census Tract disadvantage and dating violence perpetration (Foshee et al., 2008). However, our findings diverge from another study that found neighborhood poverty was positively associated with adult male victimization amongst Blacks and Whites, and female victimization among Blacks (Cunradi et al., 2000). The contrast between the adolescent and adult partner violence studies could suggest contextual disadvantage plays a larger role in adult versus adolescent partner violence. However, differences may also arise because the adolescent studies used a disadvantage index, while the adult study used the single indicator of neighborhood poverty. Our use of the index was based on our application of social disorganization theory (Browning, 2002; Sampson et al., 1997). Using an index could possibly mask associations between single contextual disadvantage indicators and dating violence. However, using a single contextual disadvantage indicator may result in spurious associations. Another possibility is that school disadvantage is better characterized by other measures (e.g., student-to-teacher ratio, average per student expenditures, percent of students receiving reduced-price lunches, etc.) which differ from those traditionally used in studying neighborhood disadvantage. Future research should examine the relevance and validity of a range of disadvantage measures in various contexts.

Gender differences in the association between relative disadvantage and victimization are consistent with gendered resource theory. Family disadvantage was positively related to females' dating violence victimization, and this relationship was stronger in more advantaged schools. This finding extends prior studies which found associations between male relative disadvantage in the couple context and adult females' victimization risk (Anderson, 1997; Atkinson et al., 2005) by linking females' dating violence victimization to relative disadvantage within the school context. It is possible that females' relative disadvantage reflects male partners' relative disadvantage, and that male partners' relative disadvantage impacts their likelihood of perpetrating dating violence. Relative disadvantage has been more strongly 
related to declines in males' self-esteem in middle-school years (Rhodes et al., 2004), supporting the notion that socioeconomic disadvantage is more threatening to masculine than feminine identities. Therefore, relatively disadvantaged male partners may feel disempowered, and use violence against female partners as a way of exerting power or gaining status. Gender differences in the salience of relative disadvantage may also explain why relative disadvantage is unrelated to males' victimization (i.e., female perpetration). Future studies utilizing data on relative disadvantage for both adolescent dating partners, as well as information on perpetration, may help explain this mechanism.

Although this study has many strengths, including the use of a large nationally-representative data set with adolescents from many community types, its limitations must also be noted. First, because questions at Wave II queried only victimization, we were unable to assess how family and school disadvantage related to dating violence perpetration. Although studies of perpetration have been undertaken using local samples, such studies have not examined interactions between family and contextual disadvantage. Future studies should address this gap.

Second, there are some limitations to the measures of victimization we used. The modified CTS2, while behaviorally specific, does not allow us to characterize the context or intention of the acts. Qualitative studies suggest heterogeneity in the circumstances of and meanings ascribed to adolescent dating violence experiences (Foshee, Bauman, Linder, Rice, \& Wilcher, 2007). For example, females' perpetration of dating violence often arises in reaction to violence initiated by their male partner (O'Keefe \& Treister, 1998). Further, we do not know if these associations generalize to more severe types of abuse. Finally, use of self-report measures with stigmatized behaviors could result in under-reporting of victimization. Although respondents self-administered this questionnaire section using A-CASI, concerns about stigma may still be present. Future studies should examine whether family and school disadvantage are differentially related to these victimization subtypes and severity levels.

Finally, we excluded a sizeable number of respondents due to their parents' non-participation. Adolescents who were included evidenced some positive selection on socioeconomic characteristics, based on adolescent responses to questions about parent education and family structure. As such, some level of selection bias could affect the estimates in the present study. Given the complexity of our models, we were unable to also apply Heckman adjustments (Heckman, 1979) to investigate these selection biases, or implement multiple imputation procedures. Future replication studies with other datasets and populations should be conducted to test the robustness of our findings.

\section{Conclusion}

In the present study, we found evidence that dating violence victimization varies appreciably across school contexts. For males, crude associations between victimization and disadvantage were explained by other individual-level factors, and school disadvantage did not modify associations between family disadvantage and victimization. In contrast, for females, family disadvantage was positively associated with psychological and physical victimization, particularly in socioeconomically advantaged schools. Such findings suggest that relative status in school affects dating violence victimication, but that girls are more vulnerable to this status differential than boys. Associations may reflect male partners' attempts to reassert masculinity due to their own relative disadvantage in the school context. Results underline the importance of examining how contexts influence and moderate individual risks for partner violence. They also suggest dating violence interventions should consider how gender and sociostructural conditions shape risk for dating violence. For example, schools with greater socioeconomic disparities possibly should be prioritized for dating violence interventions. Further, although more research is warranted examining mediating mechanisms, results also 
suggest that programs to help adolescents challenge negative aspects of traditional gender roles, or self-worth tied to relative socioeconomic position, could help to stem some forms of dating violence.

\section{References}

Aldarondo E, Sugarman DB. Risk marker analysis of the cessation and persistence of wife assault. Journal of Consulting and Clinical Psychology 1996;64(5):1010-1019. [PubMed: 8916630]

Anderson KL. Gender, status, and domestic violence: An integration of feminist and family violence approaches. Journal of Marriage and the Family 1997;59(3):655-669.

Atkinson MP, Greenstein TN, Lang MM. For women, breadwinning can be dangerous: Gendered resource theory and wife abuse. Journal of Marriage and the Family 2005;67(5):1137-1148.

Bonomi AE, Thompson RS, Anderson M, Reid RJ, Carrell D, Dimer JA, et al. Intimate partner violence and women's physical, mental, and social functioning. American Journal of Preventive Medicine 2006;30(6):458-466. [PubMed: 16704938]

Breiding MJ, Black MC, Ryan GW. Prevalence and Risk Factors of Intimate Partner Violence in Eighteen U.S. States/Territories, 2005. American Journal of Preventive Medicine 2008;34(2):112-118. [PubMed: 18201640]

Browning CR. The span of collective efficacy: Extending social disorganization theory to partner violence. Journal of Marriage and the Family 2002;64(4):833-850.

Buzy WM, McDonald R, Jouriles EN, Swank PR, Rosenfield D, Shimek JS, et al. Adolescent girls' alcohol use as a risk factor for relationship violence. Journal of Research on Adolescence 2004;14(4): 449-470.

Chaix B, Rosvall M, Merlo J. Neighborhood socioeconomic deprivation and residential instability: effects on incidence of ischemic heart disease and survival after myocardial infarction. Epidemiology 2007;18 (1):104-111. [PubMed: 17130687]

Coleman JS. Social capital in the creation of human capital. The American Journal of Sociology 1988;94:S95-S120.

Cubbin C, Santelli J, Brindis CD, Braveman P. Neighborhood context and sexual behaviors among adolescents: Findings from the National Longitudinal Study of Adolescent Health. Perspectives on Sexual and Reproductive Health 2005;37(3):125-134. [PubMed: 16150660]

Cunradi CB, Caetano R, Clark C, Schafer J. Neighborhood poverty as a predictor of intimate partner violence among white, black, and Hispanic couples in the United States: A multilevel analysis. Annals of Epidemiology 2000;10(5):297-308. [PubMed: 10942878]

Cunradi CB, Caetano R, Schafer J. Socioeconomic predictors of intimate partner violence among White, Black, and Hispanic couples in the United States. Journal of Family Violence 2002;17(4):377-389.

De Coster S, Heimer K, Wittrock SM. Neighborhood disadvantage, social capital, street context, and youth violence. Sociological Quarterly 2006;47(4):723-753.

Decker MR, Silverman JG, Raj A. Dating violence and sexually transmitted disease/HIV testing and diagnosis among adolescent females. Pediatrics 2005;116(2):E272-E276. [PubMed: 16061580]

Do DP, Finch BK, Basurto-Davila R, Bird C, Escarce J, Lurie N. Does place explain racial health disparities? Quantifying the contribution of residential context to the Black/white health gap in the United States. Soc Sci Med 2008;67(8):1258-1268. [PubMed: 18649984]

Field CA, Caetano R. Intimate partner violence in the US general population - Progress and future directions. Journal of Interpersonal Violence 2005;20(4):463-469. [PubMed: 15722502]

Fitzmaurice, GM.; Laird, NM.; Ware, JH. Applied Longitudinal Analysis. Wiley-Interscience; 2004.

Ford K, Sohn W, Lepkowski JM. Characteristics of adolescents' sexual partners and their association with use of condoms and other contraceptive methods. Family Planning Perspectives 2001;33(3): 100-132. [PubMed: 11407432]

Ford K, Sohn W, Lepkowski JM. American adolescents: Sexual mixing patterns, bridge partners, and concurrency. Sexually Transmitted Diseases 2002;29(1):13-19. [PubMed: 11773873]

Ford K, Sohn W, Lepkowski JM. Ethnicity or race, area characteristics, and sexual partner choice among American adolescents. Journal of Sex Research 2003;40(2):211-218. [PubMed: 12908128] 
Foshee VA, Bauman KE, Linder F, Rice J, Wilcher R. Typologies of adolescent dating violence Identifying typologies of adolescent dating violence perpetration. Journal of Interpersonal Violence 2007;22(5):498-519. [PubMed: 17429020]

Foshee VA, Benefield TS, Ennett ST, Bauman KE, Suchindran C. Longitudinal predictors of serious physical and sexual dating violence victimization during adolescence. Preventive Medicine 2004;39 (5):1007-1016. [PubMed: 15475036]

Foshee VA, Karriker-Jaffe KJ, Reyes HLM, Ennett ST, Suchindran C, Bauman KE, et al. What accounts for demographic differences in trajectories of adolescent dating violence? An examination of intrapersonal and contextual mediators. Journal of Adolescent Health 2008;42(6):596-604. [PubMed: 18486869]

Foshee VA, Linder F, MacDougall JE, Bangdiwala S. Gender differences in the longitudinal predictors of adolescent dating violence. Preventive Medicine 2001;32(2):128-141. [PubMed: 11162338]

Foster, H.; Hagan, J.; Brooks-Gunn, J. Age, puberty, and exposure to intimate partner violence in adolescence; Youth Violence: Scientific Approaches to Prevention. 2004. p. 151-166.

Halpern CT, Oslak SG, Young ML, Martin SL, Kupper LL. Partner violence among adolescents in opposite-sex romantic relationships: Findings from the National Longitudinal Study of Adolescent Health. American Journal of Public Health 2001;91(10):1679-1685. [PubMed: 11574335]

Halpern CT, Young ML, Waller MW, Martin SL, Kupper LL. Prevalence of partner violence in samesex romantic and sexual relationships in a National Sample of Adolescents. Journal of Adolescent Health 2004;35(2):124-131. [PubMed: 15261641]

Harris KM, Duncan GJ, Boisjoly J. Evaluating the role of "nothing to lose" attitudes on risky behavior in adolescence. Social Forces 2002;80(3):1005-1039.

Harris, KM.; Florey, F.; Tabor, J.; Bearman, PS.; Jones, J.; Udry, JR. The National Longitudinal Study of Adolescent Health: Research Design [WWW document]. Carolina Population Center, University of North Carolina at Chapel Hill; Chapel Hill, NC: 2003.

Heckman JJ. Sample selection bias as a specification error. Econometrica 1979;47(1):153-161.

Hooverdempsey KV, Bassler OC, Brissie JS. Parent Involvement - Contributions of Teacher Efficacy, School Socioeconomic-Status, and Other School Characteristics. American Educational Research Journal 1987;24(3):417-435.

Johnson MP, Leone JM. The differential effects of intimate terrorism and situational couple violence Findings from the national violence against women survey. Journal of Family Issues 2005;26(3): 322-349.

Kaestle CE, Halpern CT. Sexual intercourse precedes partner violence in adolescent romantic relationships. Journal of Adolescent Health 2005;36(5):386-392. [PubMed: 15837342]

Lehrer JA, Buka S, Gortmaker S, Shrier LA. Depressive symptomatology as a predictor of exposure to intimate partner violence among US female adolescents and young adults. Archives of Pediatrics \& Adolescent Medicine 2006;160(3):270-276. [PubMed: 16520446]

Link BG, Phelan J. Social conditions as fundamental causes of disease. Journal of Health and Social Behavior 1995:80-94. [PubMed: 7560851]

Lisabeth LD, Diez Roux AV, Escobar JD, Smith MA, Morgenstern LB. Neighborhood environment and risk of ischemic stroke: the brain attack surveillance in Corpus Christi (BASIC) Project. Am J Epidemiol 2007;165(3):279-287. [PubMed: 17077168]

Masi CM, Hawkley LC, Piotrowski ZH, Pickett KE. Neighborhood economic disadvantage, violent crime, group density, and pregnancy outcomes in a diverse, urban population. Soc Sci Med 2007;65 (12):2440-2457. [PubMed: 17765371]

Murray DM, Short BJ. Intraclass correlation among measures related to tobacco use by adolescents: Estimates, correlates, and applications in intervention studies. Addictive Behaviors 1997;22(1):112. [PubMed: 9022867]

O'Keefe M. Factors mediating the link between witnessing interparental violence and dating violence. Journal of Family Violence 1998;13(1):39-57.

O'Keefe M, Treister L. Victims of dating violence among high school students: Are the predictors different for males and females? Violence Against Women 1998;4(2):195-223. [PubMed: 12295441]

O'Malley PM, Johnston LD, Bachman JG, Schulenberg JE, Kumar R. How substance use differs among American secondary schools. Prevention Science 2006;7(4):409-420. [PubMed: 16900406] 
Oetting ER, Donnermeyer JF, Deffenbacher JL. Primary socialization theory. The influence of the community on drug use and deviance. III. Substance Use \& Misuse 1998;33(8):1629-1665. [PubMed: 9680086]

Olshen E, McVeigh KH, Wunsch-Hitzig RA, Rickert VI. Dating violence, sexual assault, and suicide attempts among urban teenagers. Archives of Pediatrics \& Adolescent Medicine 2007;161(6):539_ 545. [PubMed: 17548757]

Pallitto CC, O'Campo P. Community level effects of gender inequality on intimate partner violence and unintended pregnancy in Colombia: testing the feminist perspective. Social Science \& Medicine 2005;60(10):2205-2216. [PubMed: 15748669]

Pflieger JC, Vazsonyi AT. Parenting processes and dating violence: The mediating role of self-esteem in low- and high-SES adolescents. Journal of Adolescence 2006;29(4):495-512. [PubMed: 16297976]

Rabe-Hesketh S, Skrondal A. Multilevel modelling of complex survey data. Journal of the Royal Statistical Society 2006;169(4):805-827.

Rabe-Hesketh, S.; Skrondal, A.; Pickles, A. GLLAMM Manual. University of California, Berkeley; Berkeley, CA: 2004.

Raudenbush, SW.; Bryk, AS. Hierarchal Linear Models: Applications and Data Analysis Methods. Sage Publications; Thousand Oaks, CA: 2002.

Rhodes J, Roffman J, Reddy R, Fredriksen K, Way N. Changes in self-esteem during the middle school years: A latent growth curve study of individual and contextual influences. Journal of School Psychology 2004;42(3):243-261.

Roberts TA, Auinger P, Klein JD. Intimate partner abuse and the reproductive health of sexually active female adolescents. Journal of Adolescent Health 2005;36(5):380-385. [PubMed: 15837341]

Roberts TA, Klein JD, Fisher S. Longitudinal effect of intimate partner abuse on high-risk behavior among adolescents. Archives of Pediatrics \& Adolescent Medicine 2003;157(9):875-881. [PubMed: 12963592]

Sampson RJ. Collective regulation of adolescent misbehavior: Validation results from eighty Chicago neighborhoods. Journal of Adolescent Research 1997;12(2):227-244.

Sampson RJ, Raudenbush SW, Earls F. Neighborhoods and violent crime: A multilevel study of collective efficacy. Science 1997;277(5328):918-924. [PubMed: 9252316]

Smolkowski K, Biglan A, Dent C, Seeley J. The multilevel structure of four adolescent problems. Prevention Science 2006;7(3):239-256. [PubMed: 16773454]

Sribney, W. Likelihood-ratio test after survey/robust ML estimation. Stata; College Station, TX: 2005.

Straus, MA.; Gelles, RJ.; Steinmetz, SK. Behind closed doors: Violence in the American family. Anchor; Garden City, NY: 1980.

Straus MA, Hamby SL, Boney-McCoy S, Sugarman DB. The revised Conflict Tactics Scales (CTS2): Development and preliminary psychometric data. Journal of Family Issues 1996;17(3):283-316.

Tjaden, P.; Thoennes, N. Extent, nature, and consequences of intimate partner violence: findings from the National Violence Against Women Survey. Washington, D.C.: U.S. Department of Justice; 2000.

Turrell G, Kavanagh A, Draper G, Subramanian SV. Do places affect the probability of death in Australia? A multilevel study of area-level disadvantage, individual-level socioeconomic position and all-cause mortality, 1998-2000. J Epidemiol Community Health 2007;61(1):13-19. [PubMed: 17183009]

Udry, JR. The National Longitudinal Study of Adolescent Health (Add Health), Waves I \& II, 19941996; Wave III, 2001-2002 [machine-readable data file and documentation]. Carolina Population Center, University of North Carolina at Chapel Hill; Chapel Hill, NC: 2003.

Webber C. Revaluating relative deprivation theory. Theoretical Criminology 2007;11(1):97-120.

Wight RG, Botticello AL, Aneshensel CS. Socioeconomic context, social support, and adolescent mental health: A multilevel investigation. Journal of Youth and Adolescence 2006;35(1):115-126. 


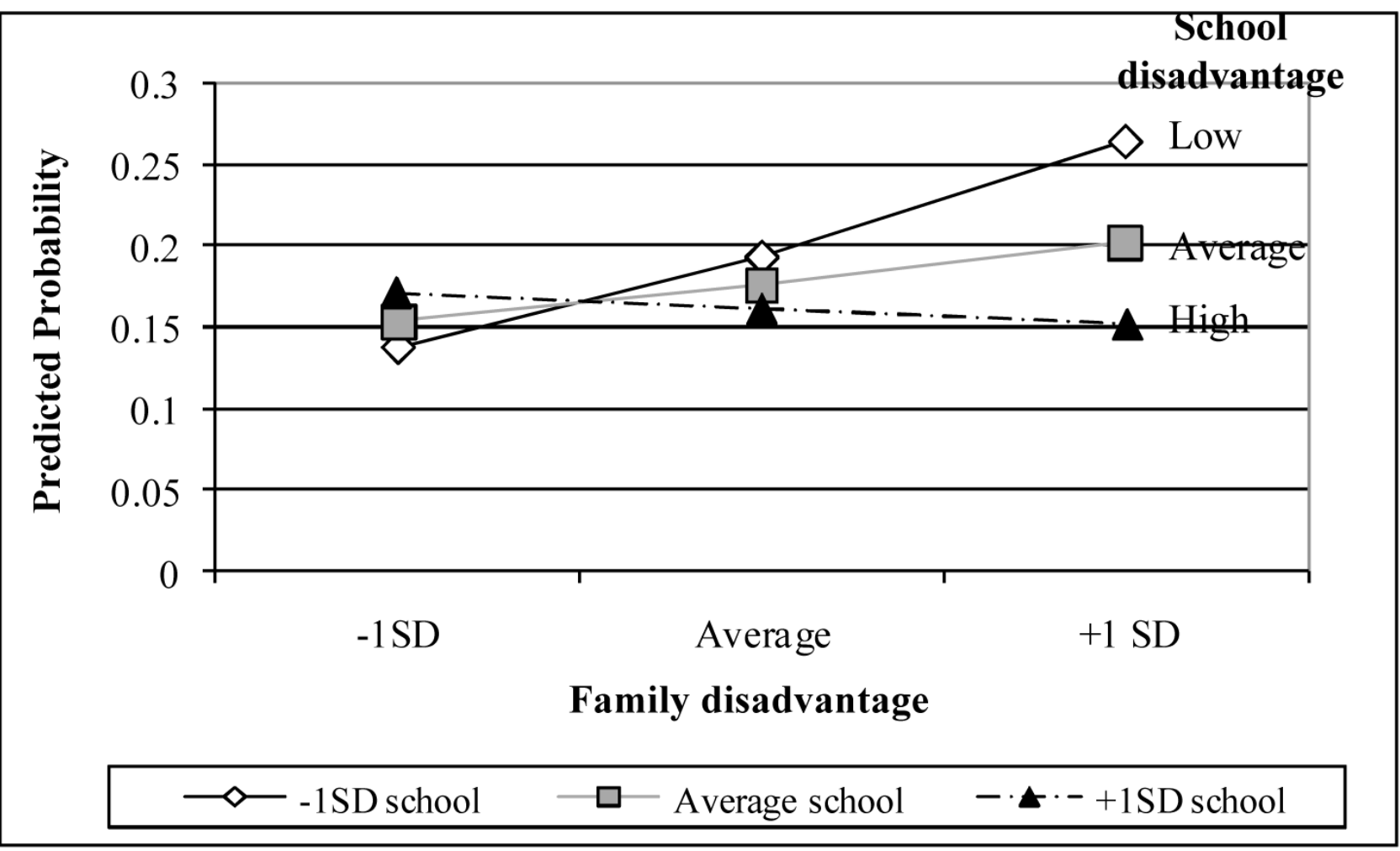

Figure 1.

Females: Predicted probability of psychological victimization by family and school disadvantage levels ${ }^{\mathrm{a}}$

aPredicted probabilities for a non-Hispanic white female who is average age within the school; high disadvantage is one standard deviation above average, and low disadvantage is one standard deviation below average. 


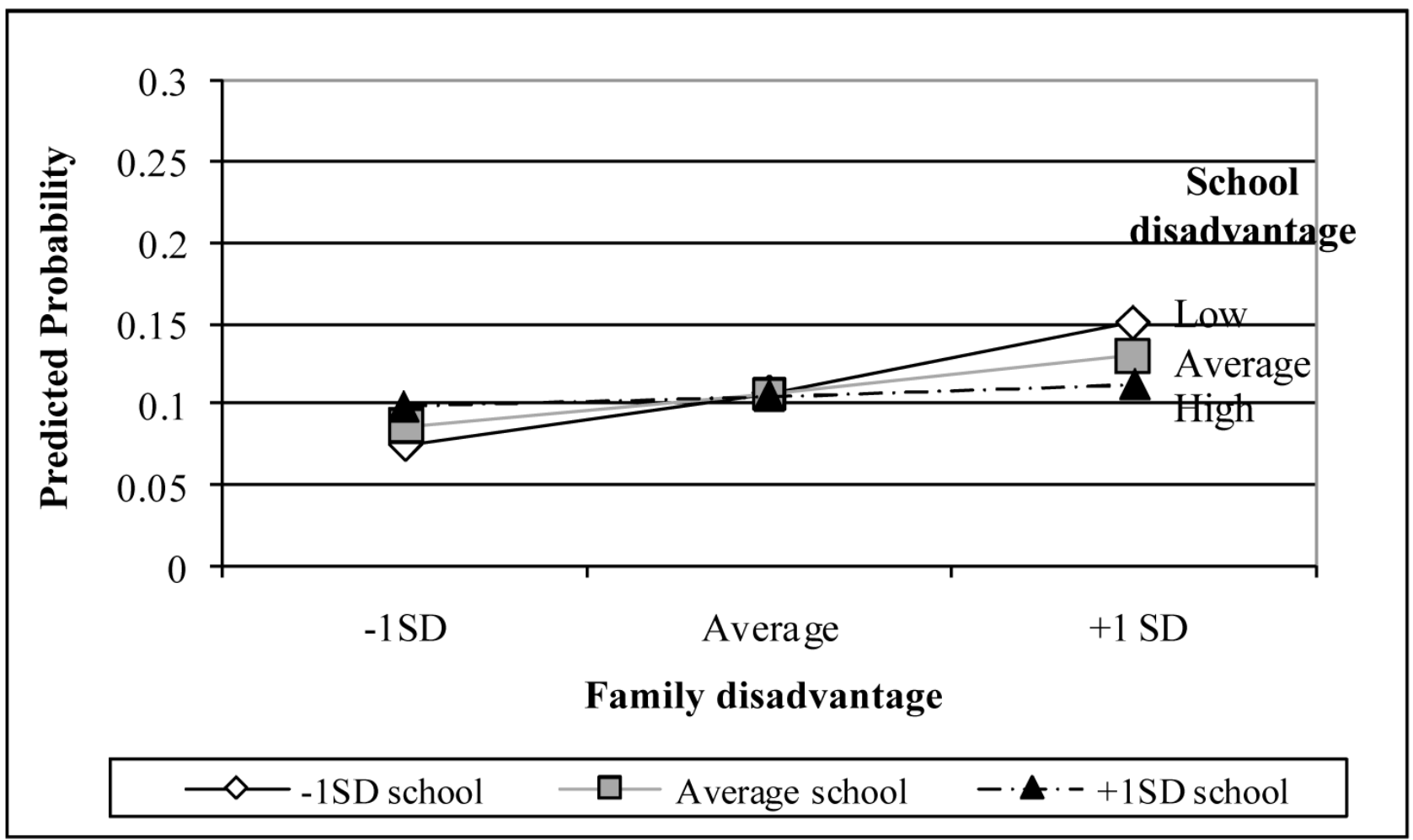

Figure 2.

Females: Predicted probability of physical victimization by family and school disadvantage levels ${ }^{\mathrm{a}}$

aPredicted probabilities for a non-Hispanic white female who is average age within the school; high disadvantage is one standard deviation above average, and low disadvantage is one standard deviation below average. 
Table 1

Descriptive statistics: Individual characteristics

\begin{tabular}{lcc}
\hline & $\begin{array}{c}\text { Females } \\
\mathbf{n = 5 , 4 4 7} \\
\mathbf{n}(\mathbf{w e i g h t e d} \%)\end{array}$ & $\begin{array}{c}\text { Males } \\
\mathbf{n = 5 , 2 0 3} \\
\mathbf{n}(\mathbf{w e i g h t e d} \%)\end{array}$ \\
\cline { 2 - 3 } Partner violence victimization & $4,269(78.1 \%)$ & \\
None & $748(13.8 \%)$ & $4,044(79.3 \%)$ \\
Psychological only & $651(13.0 \%)$ & $779(13.6 \%)$ \\
Call names, insult, or treat disrespectfully & $852(15.8 \%)$ & $514(8.6 \%)$ \\
Swear at you & $213(3.6 \%)$ & $834(15.1 \%)$ \\
Threaten you with violence & $430(8.1 \%)$ & $140(2.5 \%)$ \\
Physical & $395(7.4 \%)$ & $380(7.1 \%)$ \\
Push or shove & $120(2.0 \%)$ & $332(6.1 \%)$ \\
Throw something at you & & $104(2.1 \%)$ \\
Race/ethnicity & $3,163(71.2 \%)$ & \\
Non-Hispanic White & $1,128(14.3 \%)$ & $3,039(71.3 \%)$ \\
Non-Hispanic Black & $848(11.3 \%)$ & $975(13.4 \%)$ \\
Hispanic & $308(3.3 \%)$ & $841(11.1 \%)$ \\
Non-Hispanic Other & $-0.60(0.03)$ & $348(4.3 \%)$ \\
Family disadvantage, mean (SE) & $16.3(0.11)$ & $-0.63(0.03)$ \\
Age, mean (SE) & & $16.5(0.12)$ \\
\hline
\end{tabular}


Table 2

Descriptive statistics: School characteristics $(n=132)$

\begin{tabular}{|c|c|c|c|}
\hline & Mean (SD) & Range & $\begin{array}{l}\text { Factor } \\
\text { Loading }\end{array}$ \\
\hline \multicolumn{4}{|l|}{ Count of eligible respondents per school } \\
\hline Female respondents & $41.5(38.9)$ & $5-377$ & -- \\
\hline Male respondents & $39.3(40.8)$ & $3-378$ & \\
\hline \multicolumn{4}{|l|}{ Dating violence victimization prevalence } \\
\hline \multicolumn{4}{|l|}{ Female respondents } \\
\hline Psychological victimization & $18.7(8.4)$ & $0-41.4$ & -- \\
\hline Minor physical victimization & $8.7(5.2)$ & $0-21.4$ & -- \\
\hline \multicolumn{4}{|l|}{ Male respondents } \\
\hline Psychological victimization & $18.2(9.6)$ & $0-44.4$ & -- \\
\hline Minor physical victimization & $7.6(5.6)$ & $0-32.3$ & -- \\
\hline \multicolumn{4}{|l|}{ School disadvantage indicators } \\
\hline $\begin{array}{l}\text { Percent students not living with two biologic } \\
\text { parents }\end{array}$ & $46.6(13.7)$ & $10.5-81.3$ & 0.75 \\
\hline Percent students with unemployed parents & $5.6(4.4)$ & $0-23.6$ & 0.72 \\
\hline $\begin{array}{l}\text { Percent students in families receiving public } \\
\text { assistance }\end{array}$ & $15.0(13.8)$ & $0-55.8$ & 0.93 \\
\hline Percent parents have difficulty paying bills & $18.3(9.9)$ & $0-50.0$ & 0.73 \\
\hline $\begin{array}{l}\text { Percent students with highest parental } \\
\text { education }<\mathrm{HS}\end{array}$ & $12.8(12.0)$ & $0-65.8$ & 0.76 \\
\hline School disadvantage score ${ }^{a}$ & $0(1)$ & $-1.68-2.76$ & -- \\
\hline
\end{tabular}

${ }^{a}$ Cronbach's $\alpha=0.82$; eigenvalues 3.08, 0.70, 0.60, 0.43, 0.18 
Table 3

Bivariate model results: Analytic variables and dating violence victimization ${ }^{a}$

\begin{tabular}{|c|c|c|}
\hline & $\begin{array}{l}\begin{array}{l}\text { Female Victimization } \\
(\mathrm{n}=5,447)\end{array} \\
\text { OR }(95 \% \mathrm{CI})\end{array}$ & $\begin{array}{l}\text { Male Victimization } \\
(\mathrm{n}=5,203) \\
\text { OR }(95 \% \mathrm{CI})\end{array}$ \\
\hline \multicolumn{3}{|l|}{ Psychological Vs. None } \\
\hline \multicolumn{3}{|c|}{ Individual-level characteristics } \\
\hline Family disadvantage & $1.06(0.95-1.20)$ & $1.20(1.03-1.40)^{*}$ \\
\hline \multicolumn{3}{|l|}{ Race/ethnicity } \\
\hline Non-Hispanic White & Referent & Referent \\
\hline Non-Hispanic Black & $0.75(0.52-1.08)$ & $1.33(0.96-1.85)$ \\
\hline Hispanic & $0.73(0.51-1.04)$ & $1.04(0.72-1.52)$ \\
\hline Non-Hispanic Other & $0.81(0.47-1.38)$ & $0.84(0.48-1.47)$ \\
\hline Age (group centered) & $1.16(1.04-1.29)^{* *}$ & $1.43(1.27-1.61)^{* * *}$ \\
\hline \multicolumn{3}{|c|}{ School-level characteristics } \\
\hline School disadvantage & $0.95(0.82-1.11)$ & $1.01(0.86-1.19)$ \\
\hline School mean age & $1.34(1.14-1.57)^{* * *}$ & $1.49(1.29-1.73)^{* * *}$ \\
\hline \multicolumn{3}{|l|}{ Physical Vs. None } \\
\hline \multicolumn{3}{|c|}{ Individual-level characteristics } \\
\hline Family disadvantage & $1.20(1.03-1.40)^{*}$ & $1.33(1.14-1.56)^{* * *}$ \\
\hline \multicolumn{3}{|l|}{ Race/ethnicity } \\
\hline Non-Hispanic White & Referent & Referent \\
\hline Non-Hispanic Black & $1.06(0.77-1.47)$ & $2.68(1.77-4.07)^{* * *}$ \\
\hline Hispanic & $0.77(0.56-1.05)$ & $2.04(1.33-3.14)^{* *}$ \\
\hline Non-Hispanic Other & $0.72(0.33-1.56)$ & $1.93(0.98-3.85)^{\dagger}$ \\
\hline Age (group centered) & $1.16(1.01-1.34)^{*}$ & $1.23(1.06-1.43)^{* *}$ \\
\hline \multicolumn{3}{|c|}{ School-level characteristics } \\
\hline School disadvantage & $1.06(0.91-1.23)$ & $1.27(1.08-1.51)^{* *}$ \\
\hline School mean age & $1.33(1.16-1.54)^{* * *}$ & $1.48(1.22-1.80)^{* * *}$ \\
\hline \multicolumn{3}{|l|}{$\dagger^{\dagger}<0.10$} \\
\hline \multicolumn{3}{|l|}{${ }^{*}<0.05$} \\
\hline \multicolumn{3}{|l|}{$* * \quad \mathrm{p}<0.01$} \\
\hline \multicolumn{3}{|l|}{$* * * * 0.001$} \\
\hline
\end{tabular}


Table 4

Multilevel multinomial logistic regression results: Dating violence victimization, Females $(n=5,447)$

\begin{tabular}{|c|c|c|c|c|}
\hline & \multicolumn{4}{|l|}{ Est. $\beta(S E)$} \\
\hline & Model 1 & Model 2 & Model 3 & Model 4 \\
\hline \multicolumn{5}{|l|}{ Psychological vs. None } \\
\hline \multicolumn{5}{|l|}{ Individual-level variables } \\
\hline Family disadvantage & & $0.10(0.06)$ & $0.10(0.07)$ & $0.17(0.07)^{*}$ \\
\hline \multicolumn{5}{|l|}{ Race/ethnicity } \\
\hline Non-Hispanic White & & Ref. & Ref. & Ref. \\
\hline Non-Hispanic Black & & $-0.34(0.19)^{\dagger}$ & $-0.34(0.21)$ & $-0.33(0.20)$ \\
\hline Hispanic & & $-0.37(0.18)^{*}$ & $-0.37(0.19)^{\dagger}$ & $-0.38(0.19)^{*}$ \\
\hline Non-Hispanic Other & & $-0.25(0.27)$ & $-0.25(0.27)$ & $-0.30(0.28)$ \\
\hline Age & & $0.16(0.06)^{* *}$ & $0.16(0.06)^{* *}$ & $0.16(0.06)^{* *}$ \\
\hline \multicolumn{5}{|l|}{ School-level variables } \\
\hline School mean age & & $0.30(0.08)^{* * *}$ & $0.30(0.08)^{* * *}$ & $0.30(0.08)^{* * *}$ \\
\hline School disadvantage & & & $-0.01(0.09)$ & $-0.11(0.10)$ \\
\hline \multicolumn{5}{|l|}{ Cross-level interaction } \\
\hline $\begin{array}{l}\text { Family disadvantage * } \\
\text { School } \\
\text { disadvantage }\end{array}$ & & & & $-0.24(0.06)^{* * *}$ \\
\hline Intercept & $-1.78(0.08)^{* * *}$ & $-1.65(0.09)^{* * *}$ & $-1.65(0.09)^{* * *}$ & $-1.54(0.10)^{* * *}$ \\
\hline \multicolumn{5}{|l|}{ Psychological vs. None } \\
\hline \multicolumn{5}{|l|}{ Individual-level variables } \\
\hline Family disadvantage & & $0.19(0.08)^{*}$ & $0.17(0.09)^{*}$ & $0.23(0.09)^{*}$ \\
\hline \multicolumn{5}{|l|}{ Race/ethnicity } \\
\hline Non-Hispanic White & & Ref. & Ref. & Ref. \\
\hline Non-Hispanic Black & & $-0.04(0.16)$ & $-0.09(0.17)$ & $-0.08(0.17)$ \\
\hline Hispanic & & $-0.38(0.16)^{*}$ & $-0.42(0.17)^{*}$ & $-0.44(0.17)^{*}$ \\
\hline Non-Hispanic Other & & $-0.38(0.41)$ & $-0.40(0.41)$ & $-0.44(0.41)$ \\
\hline Age & & $0.15(0.07)^{*}$ & $0.15(0.07)^{*}$ & $0.16(0.07)^{*}$ \\
\hline \multicolumn{5}{|l|}{ School-level variables } \\
\hline School mean age & & $0.30(0.07)^{* * *}$ & $0.30(0.07)^{* * *}$ & $0.30(0.08)^{* * *}$ \\
\hline School disadvantage & & & $0.06(0.09)$ & $-0.01(0.09)$ \\
\hline \multicolumn{5}{|l|}{ Cross-level interaction } \\
\hline $\begin{array}{l}\text { Family disadvantage * School } \\
\text { disadvantage }\end{array}$ & & & & $-0.16(0.09)^{\dagger}$ \\
\hline Intercept & $-2.36(0.08)^{* * *}$ & $-2.21(0.11)^{* * *}$ & $-2.21(0.11)^{* * *}$ & $-2.13(0.11)^{* * *}$ \\
\hline \multicolumn{5}{|l|}{ Variance Estimate } \\
\hline Intercept & $0.19(0.05)$ & $0.12(0.04)$ & $0.12(0.04)$ & $0.13(0.06)$ \\
\hline Family disadvantage & & & & $0.003(0.006)$ \\
\hline
\end{tabular}




\begin{tabular}{|c|c|c|c|c|}
\hline & \multicolumn{4}{|c|}{ Est. $\beta$ (SE) } \\
\hline & Model 1 & Model 2 & Model 3 & Model 4 \\
\hline Intraclass correlation (ICC) ${ }^{a}$ & 0.05 & 0.04 & 0.04 & 0.04 \\
\hline $\begin{array}{l}\% \text { change in intercept } \\
\text { variance }^{b}\end{array}$ & -- & $-35.55 \%$ & $-35.55 \%$ & $-30.38 \%$ \\
\hline \multicolumn{5}{|l|}{${ }^{\dagger} \mathrm{p}<0.10$} \\
\hline \multicolumn{5}{|l|}{${ }^{*} p<0.05$} \\
\hline \multicolumn{5}{|l|}{${ }^{* *} \mathrm{p}<0.01$} \\
\hline \multicolumn{5}{|l|}{$* * * \quad p<0.001$} \\
\hline${ }^{a}$ Based on a level-1 logistic dis & ion with $\mathrm{v}$ & $\Pi^{2} / 3$ & & \\
\hline
\end{tabular}


Table 5

Multilevel multinomial logistic regression results: Dating violence victimization, Males $(\mathrm{n}=5,203)$

\begin{tabular}{|c|c|c|c|c|}
\hline & \multicolumn{4}{|l|}{ Est. $\beta(\mathrm{SE})$} \\
\hline & Model 1 & Model 2 & Model 3 & Model 4 \\
\hline \multicolumn{5}{|l|}{ Psychological vs. None } \\
\hline \multicolumn{5}{|l|}{ Individual-level variables } \\
\hline Family disadvantage & & $0.13(0.09)$ & $0.14(0.09)$ & $0.16(0.10)$ \\
\hline \multicolumn{5}{|l|}{ Race/ethnicity } \\
\hline Non-Hispanic White & & Ref. & Ref. & Ref. \\
\hline Non-Hispanic Black & & $0.23(0.17)$ & $0.27(0.18)$ & $0.27(0.19)$ \\
\hline Hispanic & & $-0.06(0.19)$ & $-0.02(0.21)$ & $-0.02(0.20)$ \\
\hline Non-Hispanic Other & & $-0.12(0.27)$ & $-0.10(0.27)$ & $-0.12(0.27)$ \\
\hline Age & & $0.35(0.06)^{* * *}$ & $0.35(0.06)^{* * *}$ & $0.35(0.06)^{* * *}$ \\
\hline \multicolumn{5}{|l|}{ School-level variables } \\
\hline School mean age & & $0.43(0.08)^{* * *}$ & $0.44(0.08)^{* * *}$ & $0.43(0.08)^{* * *}$ \\
\hline School disadvantage & & & $-0.05(0.09)$ & $-0.09(0.10)$ \\
\hline \multicolumn{5}{|l|}{ Cross-level interaction } \\
\hline $\begin{array}{l}\text { Family disadvantage * } \\
\text { School } \\
\text { disadvantage }\end{array}$ & & & & $-0.08(0.09)$ \\
\hline Intercept & $-1.79(0.09)^{* * *}$ & $-1.85(0.13)^{* * *}$ & $-1.86(0.13)^{* * *}$ & $-1.84(0.14)^{* * *}$ \\
\hline \multicolumn{5}{|l|}{ Physical vs. None } \\
\hline \multicolumn{5}{|l|}{ Individual-level variables } \\
\hline Family disadvantage & & $0.12(0.10)$ & $0.11(0.10)$ & $0.08(0.12)$ \\
\hline \multicolumn{5}{|l|}{ Race/ethnicity } \\
\hline Non-Hispanic White & & Ref. & Ref. & Ref. \\
\hline Non-Hispanic Black & & $0.93(0.23)^{* * *}$ & $0.89(0.25)^{* * *}$ & $0.91(0.26)^{* *}$ \\
\hline Hispanic & & $0.63(0.25)^{*}$ & $0.59(0.27)^{*}$ & $0.60(0.27)^{*}$ \\
\hline Non-Hispanic Other & & $0.72(0.34)^{*}$ & $0.70(0.34)^{*}$ & $0.69(0.35)^{*}$ \\
\hline Age & & $0.20(0.08)^{* *}$ & $0.20(0.07)^{* *}$ & $0.20(0.08)^{* *}$ \\
\hline \multicolumn{5}{|l|}{ School-level variables } \\
\hline School mean age & & $0.41(0.09)^{* * *}$ & $0.40(0.09)^{* * *}$ & $0.40(0.09)^{* * *}$ \\
\hline School disadvantage & & & $0.04(0.10)$ & $0.04(0.10)$ \\
\hline \multicolumn{5}{|l|}{ Cross-level interaction } \\
\hline $\begin{array}{l}\text { Family disadvantage } \\
\text { School } \\
\text { disadvantage }\end{array}$ & & & & $0.02(0.09)$ \\
\hline Intercept & $-2.47(0.09)^{* * *}$ & $-2.81(0.17)^{* * *}$ & $-2.81(0.17)^{* * *}$ & $-2.85(0.20)^{* * *}$ \\
\hline \multicolumn{5}{|l|}{ Variance Estimates } \\
\hline Intercept & $0.35(0.07)$ & $0.21(0.05)$ & $0.21(0.05)$ & $0.22(0.06)$ \\
\hline Family disadvantage & & & & $0.07(0.05)$ \\
\hline Statistics & & & & \\
\hline
\end{tabular}




\begin{tabular}{|c|c|c|c|c|}
\hline & \multicolumn{4}{|c|}{ Est. $\beta(\mathrm{SE})$} \\
\hline & Model 1 & Model 2 & Model 3 & Model 4 \\
\hline Intraclass correlation (ICC) ${ }^{a}$ & 0.10 & 0.06 & 0.06 & 0.06 \\
\hline $\begin{array}{l}\% \text { change in intercept } \\
\text { variance }^{b}\end{array}$ & -- & $-37.60 \%$ & $-37.60 \%$ & $-34.81 \%$ \\
\hline \multicolumn{5}{|l|}{$t_{p}<0.10$} \\
\hline \multicolumn{5}{|l|}{${ }^{*}<<0.05$} \\
\hline \multicolumn{5}{|l|}{ ** $\mathrm{p}<0.01$} \\
\hline \multicolumn{5}{|l|}{$* * * * 0.001$} \\
\hline \multicolumn{5}{|c|}{$a_{\text {Based on a level-1 logistic distribution with variance } \Pi^{2} / 3}$} \\
\hline
\end{tabular}

